\title{
Facial fractures - association with ocular injuries: A 13-year review of one practice in a tertiary care centre
}

\author{
Daniel Y Nagase MD, Douglas J Courtemanche MD MS FRCSC, Daniel A Peters MD
}

\begin{abstract}
DY Nagase, DJ Courtemanche, DA Peters. Facial fractures association with ocular injuries: A 13-year review of one practice in a tertiary care centre. Can J Plast Surg 2006;14(3):167-171.
\end{abstract}

BACKGROUND: The incidence of ocular injury associated with facial fractures has been reported to be between $0.8 \%$ and $30 \%$.

OBJECTIVE: Because of this wide range of incidences, a system to stratify the risk of ocular injury by type of facial fracture was sought. METHODS: The present study reviewed 266 patients with facial fractures to determine the risk factors for ocular injury. The anatomy of each facial fracture was classified using an orbit-centred approach according to the number of orbital walls fractured. Patients were then grouped using this classification system. Charts documenting follow-up for each patient over a minimum of one year were examined and initial emergency room presentations of patients with subsequent visual impairment were recorded.

RESULTS: The incidence of severe visual impairment and blindness was $4.5 \%$ overall. Although all facial fractures (including isolated fractures of the mandible) had a notable incidence of ocular injury, an increased number of orbital wall fractures were correlated with an increased incidence of permanent visual disability. One of 147 $(0.68 \%)$ patients without an orbital wall fracture sustained permanent severe ocular injury or blindness, while $13.5 \%$ (five of 37 ) of three-wall orbital fracture patients and 25\% (four of 16) of four-wall orbital fracture patients sustained the same injury.

CONCLUSIONS: The risk of ocular injury in complex facial fractures can be stratified by the degree of orbital wall involvement. However, because all patients with persistent visual impairment had ocular findings on initial examination, it is proposed that oculovisual testing is a more sensitive indicator of lasting ocular injuries than the type of facial fracture.

Key Words: Blindness; Facial fracture; LeFort; Mandibular fracture; Ophthalmic injury; Orbital fracture

\section{Fractures du massif facial et lésions oculaires : examen de la patientèle au bout de 13 ans dans un centre de soins tertiaires}

CONTEXTE : La fréquence des lésions oculaires associées aux fractures du massif facial varie de $0,8 \%$ à $30 \%$.

BUT : Étant donné l'écart important de fréquence, nous avons tenté d'élaborer un système de classification des risques de lésions oculaires en fonction du type de fracture du massif facial.

MÉTHODE : Nous avons passé en revue les dossiers de 266 patients ayant subi une fracture du massif facial pour déterminer les facteurs de risque de lésion oculaire. L'anatomie de chaque fracture a été répartie en fonction du nombre de parois orbitaires fracturées, selon un système de classification fondé sur l'orbite. Les patients ont ensuite été groupés selon ce système de classification. Nous avons examiné les dossiers des patients qui avaient fait l'objet d'un suivi pendant au moins un an et avons noté l'état de ceux qui se plaignaient de déficience visuelle par suite de l'accident au moment de leur arrivée à l'urgence.

RÉSULTATS : La fréquence d'une déficience visuelle importante et de la cécité s'est établie, dans l'ensemble, à 4,5 \%. Même si tous les types de fracture du massif facial, y compris la fracture isolée de la mandibule, étaient associés à une fréquence importante de lésions oculaires, les fractures des parois orbitaires étaient corrélées encore plus étroitement avec une déficience visuelle permanente. Un patient sur 147 (0,68 \%) sans fracture des parois orbitaires a éprouvé des troubles visuels graves et permanents ou la cécité contre cinq patients sur 37 (13,5\%) pour les fractures de trois parois orbitaires et quatre patients sur 16 (25\%) pour les fractures des quatre parois orbitaires.

CONCLUSIONS : Le risque de lésion oculaire dans les fractures complexes du massif facial peut être classé en fonction du degré d'atteinte des parois orbitaires. Cependant, comme tous les patients atteints de déficience visuelle permanente présentaient des lésions oculaires au moment de l'examen à l'urgence, nous sommes d'avis que les examens oculovisuels sont un indicateur plus sensible de lésions oculaires permanentes que le type de fracture du massif facial.
$\mathrm{A}$ important concern in facial fracture patients is the
possibility of ocular injury. The literature-reported inci-
dences of ophthalmic injuries occurring with facial fracture
spans from as low as $0.8 \%$ in one study (1) inclusive of all
facial fractures, to as high as $30 \%$ in a study of blowout frac-
tures (2). The visual outcomes of traumatic eye injuries are
equally as varied, from temporary blurred vision, as seen in
traumatic myadriasis, to complete blindness, as seen in severe
retinal detachment (3). Understanding the incidence of ocu-
lar injuries and when subspecialty ophthalmological manage-
ment is needed, is imperative to optimal patient care in the
facial fracture population.

Department of Plastic Surgery, University of British Columbia, Vancouver, British Columbia

Correspondence: Dr Daniel Y Nagase, A242 Shaughnessy Building, BC Children's Hospital, Box 150, 4480 Oak Street, Vancouver,

British Columbia V6H 3V4. Telephone 604-875-2291, fax 604-875-2749, e-mail dnagase@dal.ca
Many facial fracture patients present in situations that preclude a formal ophthalmic examination. Cervical spine precautions, intubation, patient unconsciousness, head injury and intoxication are just a few of the factors that can delay all but the most basic ocular and visual acuity examinations. Nevertheless, a prospective facial fracture study by al-Qurainy et al (4) demonstrated the value of basic screening tests by showing that visual acuity changes alone had a sensitivity of 93\% with respect to ocular injuries requiring immediate referral to an ophthalmologist. Recognizing that the distribution of serious ocular injuries is not equal among the various types of facial fractures (5), we have retrospectively implemented an 
TABLE 1

Summary of incidence of ophthalmic injury

\begin{tabular}{|c|c|c|c|c|c|}
\hline $\begin{array}{l}\text { Number of orbital } \\
\text { walls fractured }\end{array}$ & $\begin{array}{c}\text { Facial } \\
\text { fracture type }\end{array}$ & Total & $\begin{array}{l}\text { With } \\
\text { ophthalmic injury }\end{array}$ & Injury rate (\%) & $\begin{array}{c}\text { Injury rate by } \\
\text { number of orbital } \\
\text { walls fractured (\%) }\end{array}$ \\
\hline \multirow[t]{2}{*}{0} & Mandibular & 105 & 3 & 2.9 & 2.72 \\
\hline & Zygomatic arch only & 29 & 1 & 3.4 & \\
\hline \multirow[t]{3}{*}{1} & Blowout & 10 & 2 & 20 & 20 \\
\hline & Orbital rim & 3 & 0 & 0 & $(4 / 20)$ \\
\hline & Cranioorbital & 3 & 1 & 33.3 & \\
\hline \multirow[t]{4}{*}{2} & Zygoma & 27 & 0 & 0 & 4.3 \\
\hline & LeFort 1 and zygoma & 4 & 0 & 0 & $(2 / 46)$ \\
\hline & LeFort 2 & 6 & 0 & 0 & \\
\hline & Blowout and zygoma & 8 & 2 & 25 & \\
\hline \multirow[t]{2}{*}{4} & Panfacial and complex midfacial & 16 & 6 & 37.5 & 37.5 \\
\hline & & & & & $(6 / 16)$ \\
\hline \multirow[t]{2}{*}{ Total } & & 266 & 27 & & 10.2 \\
\hline & & & & & $(27 / 266)$ \\
\hline
\end{tabular}

orbit-centred classification system on a facial fracture population to better stratify which patients are more at risk of serious ophthalmological sequelae.

\section{PATIENTS AND METHODS}

Charts of 266 patients with facial trauma requiring operative reduction were reviewed. All patients had their initial assessment and follow-up between 1991 and 2004, by a single craniofacial surgeon. The type of facial fracture and the presence of ophthalmic complaints (including any ophthalmology follow-up) were collected for a follow-up period of at least one year. Facial fractures were first analyzed according to their location. With an orbit-centred approach, each type of facial fracture was classified by the number of orbital walls fractured in the facial injury. Patients with mandibular fractures, maxillary alveolar, LeFort 1 and zygomatic arch fractures fell into category 0 with no orbital wall involvement. Category 1 patients with single orbital wall compromise had orbital blowout, orbital rim, isolated nasoethmoid complex and isolated cranio-orbital fractures. Category 2 patients with two orbital walls fractured included those with zygomatico-orbital complex, classic LeFort 2 fractures and LeFort 2 fractures with concomitant blowout or zygoma fractures. Category 3 patients had a compromise of three orbital walls. They included any combination of cranioorbital, nasoethmoid, zygomatico-orbital complex, LeFort 2 and LeFort 3 fracture with disruption of three orbital walls. Finally, facial fractures with panorbital involvement were classified as category 4 . In the case of bilateral injuries, the side most severely affected was counted. Eye injuries were classified as severe or blinding if they involved nontreatable, nonrecoverable loss of one or more hemifields of vision in either eye or loss of central vision from macular injury. Treatable visual deficits such as diplopia were excluded from this category. One-way ANOVA was performed on the overall injury rate dataset and the blindness/severe injury dataset, respectively. Further statistical analysis of the data within each set was made with the Bonferroni test.

\section{RESULTS}

Overall, there was a trend of higher rates of ocular injury as the number of orbital wall fractures increased (Tables 1 to 5 ). Interestingly, even facial fractures with no orbital involvement had concomitant ocular injuries. The one patient who suffered from blindness in the zero orbital wall fracture category had an unusual mechanism of injury involving optic chiasm thrombosis from a single gunshot wound fracturing both mandibular condyles. This resulted in a rate of blindness of $0.68 \%$ for this group. The other three patients with ocular injuries without orbital fracture suffered from diplopia. In the single orbital wall fracture group, there was a 20\% (four of 20) incidence of ophthalmic injuries, with a 5\% (one of 20) rate of serious/blinding injuries. The patient with the serious eye injury had a retinal/choroidal rupture through the macula from a nasoorbital ethmoid facial fracture. The other three eye injury patients in the single wall fracture category had diplopia. Two of these diplopia cases occurred in the context of a blowout fracture and the third occurred in a craniofrontal orbital fracture patient. Patients with two orbital wall fractures had a $4.3 \%$ (two of 46) incidence of ophthalmic injury with $2.2 \%$ (one of 46) serious/blinding. The one patient with serious visual impairment had traumatic retinopathy after a severe blowout and zygomatico-orbital complex fracture. The other patient had a small globe puncture causing only temporary visual deficit. The patterns of injury and blindness in the three- and four-wall fracture categories are more varied and are detailed in Table 5.

One-way ANOVA of ocular injury rates by degree of orbital wall fracture was statistically significant $(\mathrm{P}<0.05)$. 
TABLE 2

Incidence of severe visual impairment or blindness

\begin{tabular}{|c|c|c|c|c|c|}
\hline $\begin{array}{l}\text { Number of orbital } \\
\text { walls fractured }\end{array}$ & $\begin{array}{c}\text { Facial } \\
\text { fracture type }\end{array}$ & Total & $\begin{array}{c}\text { With severe } \\
\text { ophthalmic injury }\end{array}$ & Injury rate $(\%)$ & $\begin{array}{c}\text { Injury rate by } \\
\text { number of orbital } \\
\text { walls fractured (\%) }\end{array}$ \\
\hline \multirow[t]{2}{*}{0} & Mandibular & 105 & 1 & 1 & 0.68 \\
\hline & Zygomatic arch only & 29 & 0 & 0 & \\
\hline \multirow[t]{3}{*}{1} & Blowout & 10 & 0 & 0 & 5 \\
\hline & Orbital rim & 3 & 0 & 0 & $(1 / 20)$ \\
\hline & Cranioorbital & 3 & 0 & 0 & \\
\hline \multirow[t]{4}{*}{2} & Zygoma & 27 & 0 & 0 & 2.2 \\
\hline & LeFort 1 and zygoma & 4 & 0 & 0 & $(1 / 46)$ \\
\hline & LeFort 2 & 6 & 0 & 0 & \\
\hline & Blowout and zygoma & 8 & 1 & 25 & \\
\hline \multirow[t]{2}{*}{4} & Panfacial and complex midfacial & 16 & 4 & 25.0 & 25 \\
\hline & & & & & $(4 / 16)$ \\
\hline \multirow[t]{2}{*}{ Total } & & 266 & 12 & & 4.5 \\
\hline & & & & & $(12 / 266)$ \\
\hline
\end{tabular}

TABLE 3

Presentation of ophthalmic injury

\begin{tabular}{lc}
\hline Presentation & $\mathbf{n}$ \\
\hline Diplopia & 8 \\
Decreased visual acuity & 10 \\
Globe rupture & 4 \\
Significant periorbital ecchymosis & 1 \\
Initial emergency room assessment not available & 4 \\
Total & 27 \\
\hline
\end{tabular}

There was an overall trend of increasing incidences of ophthalmic injury with increasing degrees of orbital wall fracture. This trend was statistically significant by Bonferroni test between fractures without orbital wall disruption and fractures affecting three and four orbital walls $(\mathrm{P}<0.05)$. The increase in ocular injury rate is also statistically significant between the two orbital wall fracture category and the three and four orbital wall categories $(\mathrm{P}<0.05)$. The single orbital wall fracture group appears to break this trend by having a higher rate of ocular injury than the two orbital wall fracture group. However, this difference is not statistically significant. Neither is the difference in ocular injury rates between the single orbital wall fracture group and the three- and four-wall orbital fracture groups. There was no statistically significant increase in ocular injury rates by Bonferroni test between the three-and four-wall orbital fracture groups

Blindness and severe injury rates also increased with higher degrees of orbital disruption. Between the no orbital wall fracture group and the three-and four-wall fracture groups, the increase in blindness and severe injury rates was statistically significant $(\mathrm{P}<0.05)$. There was also a statistically significant difference
TABLE 4

Distribution of blindness and severe visual impairment

\begin{tabular}{lcc}
\hline & Blindness (n) & Severe visual impairment (n) \\
\hline $\begin{array}{l}\text { Panfacial and complex } \\
\text { midfacial }\end{array}$ & 2 & 2 \\
LeFort 3/complex & 1 & 3 \\
$\quad$ midfacial & & 1 \\
Blowout and zygoma & 0 & 1 \\
Nasoorbital ethmoid, frontal & 0 & \\
$\quad$ bone and zygoma & & 0 \\
Nasoethmoid & 1 & 0 \\
Mandibular & 1 & 7 \\
Total & 5 & \\
\hline
\end{tabular}

between the one orbital wall fracture and the four orbital wall fracture groups $(\mathrm{P}<0.05)$ but not between the one-wall and three-wall orbital fracture groups $(\mathrm{P}=0.730)$ or the one-wall and two-wall fracture groups $(\mathrm{P}=1.00)$. Comparing the two orbital wall fracture group with the four-wall fracture group, the blindness/severe injury rates show a statistically significant increase $(\mathrm{P}<0.05)$. However, this increase was not statistically significant between the two-wall and three-wall fracture groups $(\mathrm{P}=0.101)$. Furthermore, there was no statistically significant increase in blindness/severe injury rates between the three- and four-wall fracture groups $(\mathrm{P}=0.538)$.

Diplopia was the most common ophthalmic injury, accounting for $33.3 \%$ of all eye injuries (Figure 1). However, not all of these patients had documentable diplopia on presentation to the emergency room, because one patient had massive periorbital swelling that precluded a formal binocular eye exam. Retinal and choroid injuries were the next most common, making up $22.2 \%$ of all ophthalmic injuries. They 
TABLE 5

Distribution by type of ophthalmic injury

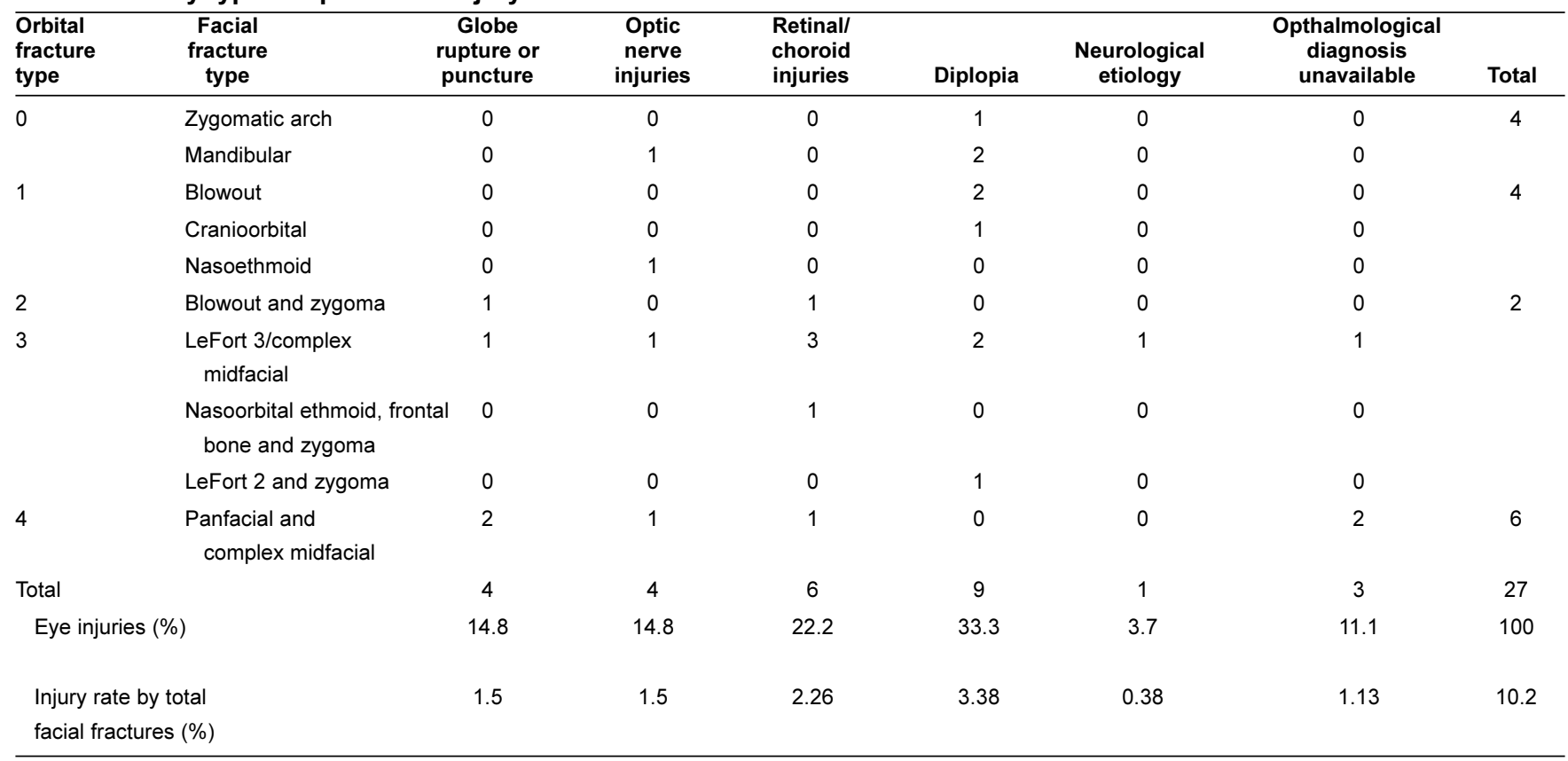

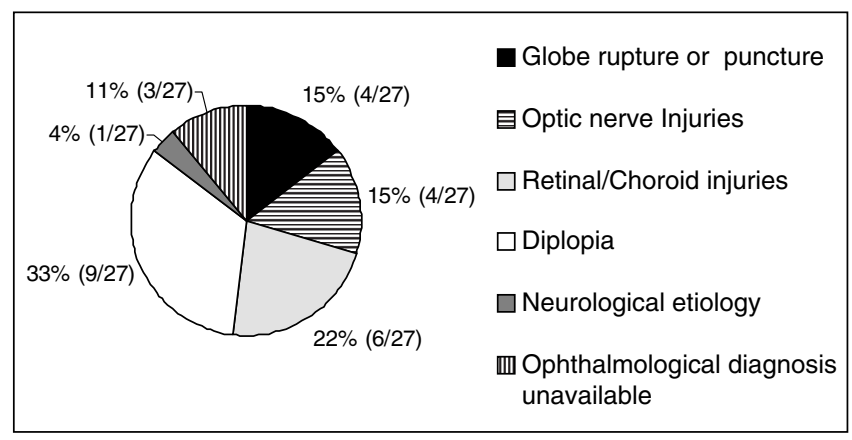

Figure 1) Type of ophthalmic injury

were seen most commonly in facial fractures involving three or four orbital walls. The next most common injuries were globe rupture/puncture and optic nerve injuries, each accounting for $14.8 \%$ of all eye injuries. One patient had a suspected transient ischemic attack causing visual disturbance. This was categorized as an ocular injury of neurological origin. Three patients had visual disturbances and/or ophthalmological referral noted in their chart without any ophthalmological diagnosis.

\section{DISCUSSION}

Based on our orbit-centred classification system, there is a trend toward higher rates of ophthalmic injury with increasing disruption of the orbit. The lack of a standardized classification system for facial fractures with respect to the orbit is partly responsible for the very wide range of ocular injury incidences reported in the facial fracture literature today (6). Nevertheless, we found that our incidence of ophthalmic injury was grossly comparable with the injury rates in the literature. Despite the selection bias inherent to a specialized craniofacial practice, our overall ophthalmological injury rate was $10.2 \%$. This is comparable with the ophthalmological complication rate of $12.6 \%$ by Cooter and David (7) in a review of 2516 facial fracture patients. The difference is that the study by Cooter and David is based on the number of patients with facial fracture who had ophthalmological signs and symptoms on presentation. The current study, on the other hand, shows ophthalmological complications being persistent on follow-up. Spontaneously resolving injuries such as conjunctival hemorrhage were not counted in the study, possibly accounting for the slightly lower injury rate.

A significant limitation of the present study was that not all patients had ophthalmological evaluation and/or follow-up. Patients only had ophthalmological evaluation if they reported visual symptoms or had ophthalmological findings during their treatment and follow-up period. Therefore, ophthalmic injuries with minor or temporary visual consequences were unrepresented. Furthermore, the possibility existed that patients with clinically silent eye injuries with grave consequences outside the follow-up period of one year were missed. Angle recession and peripheral retinal detachments may be asymptomatic over the short term only to cause problems months and sometimes years later (8).

A comparison of our results with that of the literature with respect to blindness and severe visual impairment was more difficult. We found an overall blindness/severe visual impairment rate of $4.5 \%$, while Cooter and David (7) reported a rate of $0.8 \%$ in their study. At the other end of the spectrum, a study by Holt and Holt (5) of 727 cases showed an incidence of serious eye injuries or blindness in $14.4 \%$ of patients. However their study had a significant selection bias in that all study patients were referral patients to ophthalmology. When the overall rate of $4.5 \%$ was broken down according to facial fracture severity, the data become more illustrative in comparison 
with current literature. A combination of our category 3 and category 4 facial fracture groups was comparable with the midfacial fracture population studied by Ashar et al (9). Our study yielded a combined blindness/severe visual impairment rate of $17 \%$ (nine of 53 ), which was comparable with the rate of 20.4\% (10 of 49) found by Ashar et al.

Many factors influence the likelihood of ocular injury in the facial fracture population. Although the current study examined fracture location and orbital involvement, mechanism of injury also played a role. The issue of high velocity versus low velocity mechanism of injury was interesting to consider in the setting of craniofacial trauma. High velocity impacts do not affect all parts of the head equally. In a sudden deceleration setting such as a motor vehicle accident, the deceleration forces experienced by the globe of the eye can vary drastically depending on the position of the head at the moment of impact. If the facial bones bear the brunt of the impact, they can serve a mitigating function by distributing the impulse of deceleration over a longer time period, thereby reducing the peak deceleration experienced by other parts of the head such as the brain and the eye. Facial fractures could therefore serve a protective role against acceleration injuries to the globe such as commotio retinae, macular edema and retinal detachment. Though al-Qurainy et al (4) did not overtly propose this in their paper, their inclusion of amnesia, not mechanism of injury, in the criteria for predicting eye injury alludes to the possibility that the actual deceleration experienced by the globe may be more closely correlated with concussive symptoms from deceleration of the brain than with the mechanism of injury.

Population data regarding cervical spine injuries in the facial fracture versus nonfacial fracture population would appear to support this proposition (10). A study of 13,834 trauma patients noted a statistically significant lower incidence of cervical spine injuries in motor vehicle casualties with facial fractures over those without. Thus, the case can be made that forces at the level of the basal skull and cervical spine are reduced in impacts that involve collapse of the facial skeleton. The eye could also be a beneficiary of such a deceleration mitigating effect, so long as it is not directly involved in the impact. Nonetheless, the results of the study are inconclusive with respect to such a theory. Although one-half of all retinal/choroid injuries occurred in the LeFort 3/complex

\section{REFERENCES}

1. MacKinnon CA, David DJ, Cooter RD. Blindness and severe visual impairment in facial fractures: An 11 year review. Br J Plast Surg 2002;55:1-7.

2. Shere JL, Boole JR, Holtel MR, Amoroso PJ. An analysis of 3599 midfacial and 1141 orbital blowout fractures among 4426 United States army soldiers, 1998-2000. Otolaryngol Head Neck Surg 2004;130:164-70.

3. Freeman HM, McDonald PR, Scheie HG. Ocular Trauma. Freeman HM, ed. New York: Appleton-Century-Crofts; 1979.

4. al-Qurainy IA, Titterington DM, Dutton GN, Stassen LF, Moos KF, el-Attar A. Midfacial fractures and the eye: The development of a system for detecting patients at risk of eye injury. Br J Oral Maxillofac Surg 1991;29:363-67.

5. Holt GR, Holt JE. Incidence of eye injuries in facial fractures: An analysis of 727 cases. Otolaryngol Head Neck Surg 1983;91:276-9. midfacial fracture population, the small numbers (six patients) and the fact that direct impact to the eye could not be ruled out in these injuries make it hard to draw a meaningful conclusion from the data.

The incidence of ophthalmological sequelae after facial fracture raises key management issues. Certain subsets of facial fractures experience very low rates of ophthalmic injury, whereas others, notably complex fractures involving the orbit, have incidences of ophthalmic injury that would seem to warrant routine ophthalmological referral. However, the authors would argue that the nature of the fracture alone is not an indicator for or against further subspecialty management. In fact, the low incidence of ophthalmic injury in mandibular fractures would be a poor reason not to refer to an ophthalmologist, especially in the presence of visual signs and symptoms. The most comprehensive prospective study to date on the topic of ophthalmic injury and facial fractures by al-Qurainy et al (4) concluded that visual acuity is the single most sensitive and specific single predictor of ophthalmic injury. Their study of 363 facial fracture patients revealed that visual acuity alone was able to identify $93 \%$ of those requiring early ophthalmological referral. Because a number of conditions identified in their paper as requiring early referral to an ophthalmologist are in fact conditions treatable by the facial surgeon with fracture reduction (retrobulbar hemorrhage and optic nerve compression), the actual percentage of patients requiring urgent ophthalmological referral who are missed based on an examination of visual acuity alone may in fact be lower.

It is possible that an even higher sensitivity could be achieved with testing for a relative afferent papillary deficit. A Marcus Gunn pupil is considered to be the most sensitive indicator of visual tract injury, even when visual acuity is still normal (11). Thus, even an unconscious patient could be easily assessed in the emergency room regarding the urgency for ophthalmic referral. Our experience has been that all significant ophthalmic injuries in our patient population had clinically apparent signs or symptoms. Except in the three cases where ophthalmological consultations and emergency room assessments were not available, all 27 patients in our study who had lasting ophthalmological complications had symptoms or signs on presentation.

6. Lim LH, Lam LK, Moore MH, Trott JA, David DJ. Associated injuries in facial fractures: Review of 839 patients. Br J Plast Surg 1993;46:635-38.

7. Cooter RD, David DJ. Computer-based coding of fractures in the craniofacial region. Br J Plast Surg 1989;42:17-26.

8. Benson WE, Shakin J, Sarin LK. Blunt trauma. In: Duane TD, ed. Clinical Ophthalmology. New York: Lippincott-Raven, 1995:1-14.

9. Ashar A, Kovacs A, Khan S, Hakim J. Blindness associated with midfacial fractures. J Oral Maxillofac Surg 1998;56:1146-50.

10. Oller DW, Meredith JW, Rutledge R, et al. The relationship between face or skull fractures and cervical spine and spinal cord injuries: A review of 13,834 patients. Accid Anal Prev 1992;24:187-92.

11. Girotto JA, Gamble WB, Robertson B, et al. Blindness after reduction of facial fractures. Plast Reconstr Surg 1998;102:1821-34. 